\title{
Chronic ketamine reduces the peak frequency of gamma oscillations in mouse prefrontal cortex ex vivo
}

\author{
James M. McNally*, Robert W. McCarley and Ritchie E. Brown \\ Laboratory of Neuroscience, Department of Psychiatry, VA Boston Healthcare System, Harvard Medical School, Brockton, MA, USA
}

Edited by:

Bernat Kocsis, Harvard Medical

School, USA

\section{Reviewed by:}

Tamas Kiss, Pfizer Inc., USA

Peter Uhlhaas, University of Glasgow, UK

Tatiana Korotkova, Leibniz Institute for Molecular Pharmacology (FMP)/

NeuroCure Cluster of Excellence,

Germany

\section{${ }^{*}$ Correspondence:}

James M. McNally, Department of

Psychiatry, VA Boston Healthcare

System, Harvard Medical School, 940

Belmont Street, Brockton, MA 02301,

USA

e-mail: james_mcnally@

hms.harvard.edu

\begin{abstract}
Abnormalities in EEG gamma band oscillations (GBO, 30-80 Hz) serve as a prominent biomarker of schizophrenia (Sz), associated with positive, negative, and cognitive symptoms. Chronic, subanesthetic administration of antagonists of $\mathrm{N}$-methyl-D-aspartate receptors (NMDAR), such as ketamine, elicits behavioral effects, and alterations in cortical interneurons similar to those observed in Sz. However, the chronic effects of ketamine on neocortical GBO are unknown. Thus, here we examine the effects of chronic (five daily i.p. injections) application of ketamine $(5$ and $30 \mathrm{mg} / \mathrm{kg}$ ) and the more specific NMDAR antagonist, MK$801(0.02,0.5$, and $2 \mathrm{mg} / \mathrm{kg})$, on neocortical GBO ex vivo. Oscillations were generated by focal application of the glutamate receptor agonist, kainate (KA), in coronal brain slices containing the prelimbic cortex. This region constitutes the rodent analog of the human dorsolateral prefrontal cortex, a brain region strongly implicated in Sz-pathophysiology. Here we report the novel finding that chronic ketamine elicits a reduction in the peak oscillatory frequency of KA-elicited oscillations (from 47 to $40 \mathrm{~Hz}$ at $30 \mathrm{mg} / \mathrm{kg}$ ). Moreover, the power of GBO in the $40-50 \mathrm{~Hz}$ band was reduced. These findings are reminiscent of both the reduced resonance frequency and power of cortical oscillations observed in Sz clinical studies. Surprisingly, MK-801 had no significant effect, suggesting care is needed when equating Sz-like behavioral effects elicited by different NMDAR antagonists to alterations in GBO activity. We conclude that chronic ketamine in the mouse mimics GBO abnormalities observed in Sz patients. Use of this ex vivo slice model may be useful in testing therapeutic compounds which rescue these GBO abnormalities.
\end{abstract}

Keywords: gamma oscillations, NMDA receptors, ketamine, schizophrenia, prefrontal cortex

\section{INTRODUCTION}

Mounting evidence suggests that the symptoms of neuropsychiatric disorders, such as schizophrenia (Sz), arise from a failure of the brain to properly integrate activity across local and distributed neuronal circuitry $(1-3)$. Neuronal oscillations represent an essential mechanism responsible for such neural integration, providing temporal coordination of neuronal activity (4). In Sz patients, numerous clinical studies have observed abnormalities in oscillatory processes (5), particularly those in the gamma frequency band (gamma band oscillations, GBO; $30-80 \mathrm{~Hz}$ ). GBO activity has been suggested to be critical for a number of sensory and cognitive tasks (6). As such, impaired GBO, particularly in prefrontal cortical regions, likely underlie positive, negative, and cognitive symptoms in $\mathrm{Sz}(3,7)$.

Over the last few decades, administration of psychotomimetic agents, such as the $N$-methyl-D-aspartate receptor (NMDAR) antagonist, ketamine, have provided the most reliable and widely used means to mimic Sz-like symptoms, and currently represents the "gold-standard" for modeling this disorder in both humans, and animals (8-10). Recent in vivo rodent studies have shown that acute systemic administration of NMDAR antagonists leads to a significant potentiation of spontaneous GBO activity in frontal cortex (11-13). Such findings have been largely confirmed ex vivo by our lab and others $(14,15)$. However, chronic application of
NMDAR antagonists arguably represents a more useful means to model Sz, since chronic administration causes structural alterations in neocortical circuitry similar to those observed in $\mathrm{Sz}$ patients $(16,17)$. However, to what extent chronic administration of ketamine and other NMDA receptor antagonists mimic Sz-like GBO abnormalities is not well understood. Thus, here we explore the effect of systemic, chronic administration of ketamine and the more specific NMDAR antagonist, MK-801 on GBO. In order to focus on changes occurring specifically in the neocortical circuitry, experiments were performed ex vivo, in slices containing the mouse prelimbic cortex (PrL), the rodent analog of the human dorsolateral prefrontal cortex (18), a region heavily implicated in many of the cognitive impairments associated with $\mathrm{Sz}$ (19, 20). GBO were elicited in submerged neocortical slices using our established method (15) utilizing brief, focal application of the glutamate receptor agonist kainate (KA).

\section{MATERIALS AND METHODS \\ ANIMALS}

Adult (>P91) heterozygous GAD67-GFP "knock-in" mice (Swiss Webster background), which express GFP under control of the promoter for GAD67 (21) of either sex were utilized for this work. As determined previously in McNally et al. (15), there are no significant sex-dependent differences in KA-elicited GBO in these mice. 
While we did not take specific advantage of the GFP labeling in the GAD67-GFP line in this study, our previous work examining the effects of acute NMDAR antagonist treatment on GBO activity was performed using this mouse line. Thus, we utilized the same line for the chronic studies reported here, allowing us to more accurately compare our present findings to those reported earlier. Mice were housed at the VA Boston Healthcare System, Brockton campus under constant temperature $\left(23^{\circ} \mathrm{C}\right)$ and a $12 \mathrm{~h}: 12 \mathrm{~h}$ light-dark cycle with food and water available ad libitum. All experiments were carried out in accordance with the American Association for Accreditation of Laboratory Animal Care's policy on care and use of laboratory animals and were approved by the local Institutional Animal Care and Use Committee.

Chronic drug administration was conducted similar to the manner described in Behrens et al. (22). Mice were given daily i.p. injections of either ketamine-HCl ( 5 or $30 \mathrm{mg} / \mathrm{kg}$ ), MK-801 $(0.02,0.5$ or $2 \mathrm{mg} / \mathrm{kg})$, or an equivalent volume of saline $(<0.5 \mathrm{~mL})$ for 5 days. The efficacy of these dosages for producing altered interneuronal parvalbumin and/or GAD67 expression reminiscent of that seen in postmortem $\mathrm{Sz}$ brains was determined in previous studies $(16,23-25)$. Mice injected with NMDAR antagonists exhibited increased locomotion for $1-2 \mathrm{~h}$ following treatment, as would be expected given the previous behavioral literature using these agents (8). However, this behavioral response was not characterized in detail. Twenty-four hours following the final drug/saline injection, animals were sacrificed and utilized as described below. Injectable Ketamine- $\mathrm{HCl}$ was obtained from Bioniche Pharma (Galway, Ireland), and MK-801 from Ascent Scientific (Bristol, UK).

\section{SLICE PREPARATION}

Coronal slices containing the PrL were prepared as previously described in McNally et al. (15). Briefly, mice were deeply anesthetized using isoflurane, then quickly decapitated. The brain was removed and placed into ice cold modified artificial cerebrospinal fluid (ACSF) containing: (in millimoles) 252 Sucrose, $1.8 \mathrm{KCl}, 1.2 \mathrm{KH}_{2} \mathrm{PO}_{4}, 2 \mathrm{MgSO}_{4}, 25.6 \mathrm{NaHCO}_{3}$, and 10 glucose saturated with $95 \% \mathrm{O}_{2} / 5 \% \mathrm{CO}_{2} .450 \mu \mathrm{m}$ slices were cut between +2.96 and $+1.54 \mathrm{~mm}$ with respect to bregma [according to the Franklin/Paxinos atlas (26)] using a Vibratome 3000 (Vibratome, Bannockburn, IL, USA). Slices were then transferred into a prechamber (BSC-PC; Warner Instruments) containing ACSF: (in millimoles) $124 \mathrm{NaCl}, 1.8 \mathrm{KCl}, 1.2 \mathrm{KH}_{2} \mathrm{PO}_{4}, 2 \mathrm{CaCl}_{2}$, $1.3 \mathrm{MgSO}_{4}, 25.6 \mathrm{NaHCO}_{3}$, and 10 glucose, continuously bubbled with $95 \% \mathrm{O}_{2} / 5 \% \mathrm{CO}_{2}(\mathrm{pH} 7.4)$. Slices were allowed to recover for at least $1 \mathrm{~h}$ before use. For recording, slices were transferred to a submersion-style recording chamber (RC27L; Warner Instruments) and constantly perfused $(5 \mathrm{~mL} / \mathrm{min})$ with warm $\operatorname{ACSF}\left(30^{\circ} \mathrm{C}\right)$.

\section{ELICITATION OF GBO IN VITRO}

As described in McNally et al. (15), extracellular field potential activity was recorded using glass micropipettes (2-5 M $\Omega$ ) filled with ACSF and positioned $\sim 50 \mu \mathrm{m}$ deep in the PrL (Layer II/III). Oscillatory activity was elicited by a brief ( $80 \mathrm{~ms} @ 30$ psi) focal application of KA ( $1 \mathrm{mM})$ onto the PrL slice in close apposition to the location of the field potential electrode using a picospritzer
(General Valve Corp.). Field potentials elicited by KA application were amplified using the $100 \times$ gain DC-coupled current-clamp mode of a Multiclamp700B amplifier (Axon Instruments). Signals were digitized at $10 \mathrm{kHz}$ using a Digidata 1322A 16-bit data acquisition system (Axon Instruments), then filtered between $1 \mathrm{kHz}$ and $0.1 \mathrm{~Hz}$ using pClamp 9.2 (Axon Instruments) and stored on a PC hard drive.

\section{ANALYSIS OF KA-ELICITED OSCILLATIONS}

Kainate-elicited oscillations were characterized using both timefrequency, and power spectral density (PSD) analysis. Grand average time-frequency plots (Figure 1) were generated in Igor Pro (Wavemetrics), by performing short-time Fourier transform analysis ( $1 \mathrm{~Hz}$ resolution) on individual LFP records of elicited oscillatory activity. Time-frequency data was then averaged across all animals in each treatment group. For data presented in Figures 2 and 3, PSD profiles were generated by Fourier transform analysis of field potential recordings using both Clampfit (axon) and Igor Pro. PSD were calculated from a $30 \mathrm{~s}$ epoch of the field potential trace starting $2.5 \mathrm{~s}$ following application of KA, following dissipation of the mechanically evoked transient. KA-elicited oscillations were generated three consecutive times at 5 min intervals. Only slices yielding consistent PSD profiles across all trials $(<10 \%$ difference in peak power, frequency) were used for analysis. To analyze the time course of oscillatory activity, the $30 \mathrm{~s}$ epoch of KA-elicited activity was broken up into six $5 \mathrm{~s}$ epochs; PSD profiles $(1.2 \mathrm{~Hz}$ resolution) for each epoch were generated, and then averaged across the three trials to provide the average PSD over each epoch for each slice. Recordings were performed on one to three slices from each experimental animal. For each animal, PSD data from individual slices were averaged to give the average PSD profile for each animal. These values were then used for comparison between treatment groups.

Three measures from each PSD segment were used to characterize the oscillations: peak power, peak frequency, and total GBO power. Peak power was defined as the highest amplitude in the averaged PSD $(>10 \mathrm{~Hz}$, bins of $1.2 \mathrm{~Hz})$. The frequency at which the peak power was observed was defined as the peak frequency. Total GBO power was determined by integration of averaged PSD between 40 and $50 \mathrm{~Hz}$, which represents roughly the average peak frequency of the oscillatory response observed under control (no drug treatment) conditions $\pm 5 \mathrm{~Hz}$. This narrow frequency band was chosen to reduce variability of the PSD measures, when compared between groups of animals, i.e., drug treated vs. saline controls [note: this band is narrower than that used in our previous study (15) where we performed a within-animal (within-slice) comparison of the effects of NMDAR antagonists].

\section{STATISTICAL ANALYSIS}

Overall analysis of chronic drug effects were initially tested using repeated measures ANOVA. Further analyses of the results were performed using Student's $t$-test for statistical comparison of individual epochs of oscillatory response. All statistical analysis was performed using SPSS 10 (SPSS Inc.). Differences were considered to be significant at $p<0.05$. Averaged values reported in this manuscript are expressed as mean \pm SEM. 

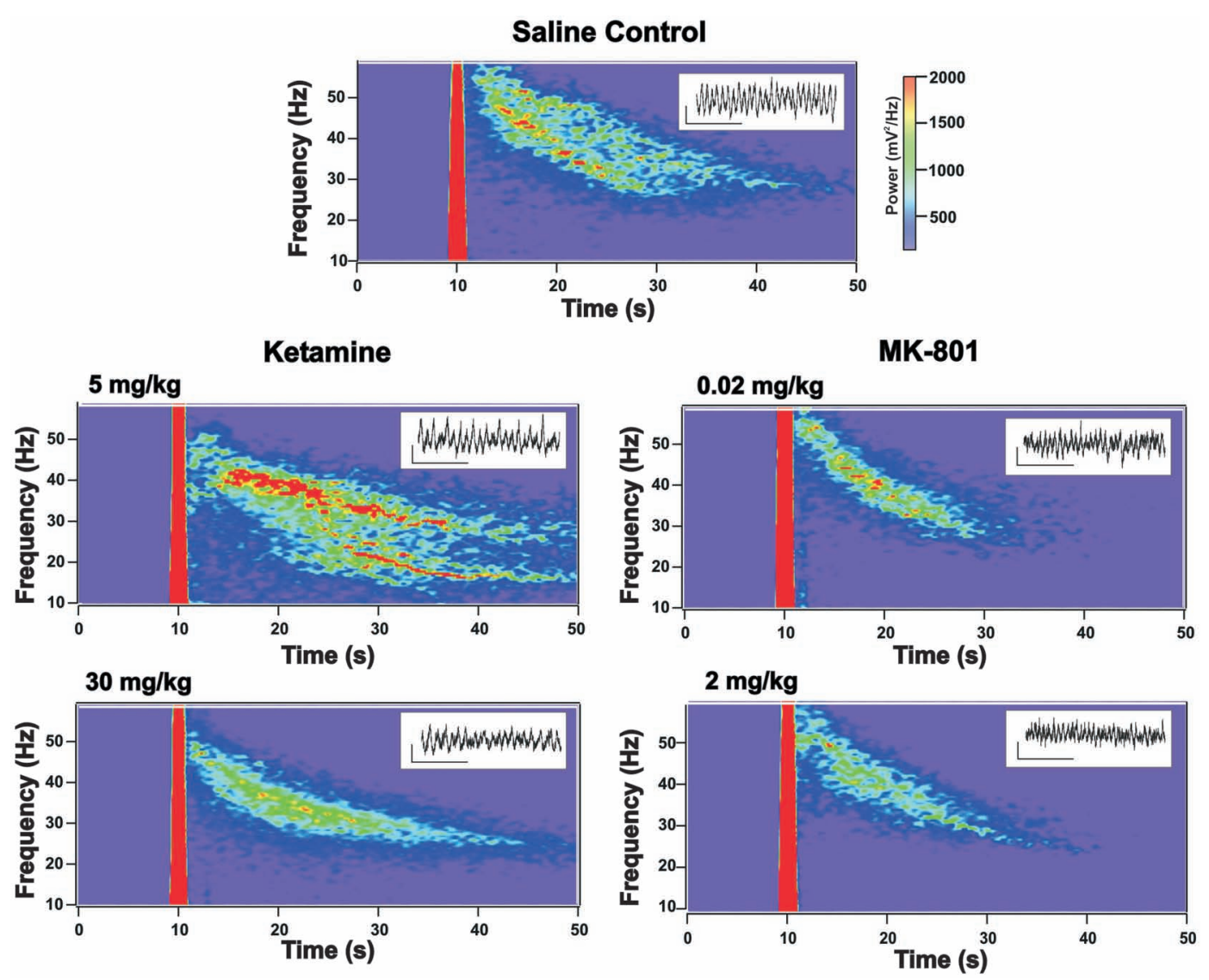

FIGURE 1 | Grand average of kainate (KA) elicited oscillatory response in prelimbic cortex (PrL) slices prepared from mice receiving chronic administration of NMDAR antagonists.

Time-frequency spectrograms show the average KA-elicited oscillatory response from acute PrL slices obtained from mice receiving chronic injections of saline (control), ketamine ( 5 and $30 \mathrm{mg} / \mathrm{kg}$ ), or MK-801 $(0.02$ and $2 \mathrm{mg} / \mathrm{kg}$ ). Note: the mechanical transient associated with $\mathrm{KA}$ application appears as a thick red line due to oversaturation. Compared to saline treated controls, the elicited response in slices from mice chronically treated with $30 \mathrm{mg} / \mathrm{kg}$ ketamine shows a reduction in the

\section{RESULTS}

\section{CHRONIC KETAMINE DECREASES THE PEAK FREQUENCY OF PrL GBO}

To evaluate the effects of chronic ketamine on KA-induced oscillations, adult mice were given five daily, i.p. injections of ketamine, a treatment paradigm similar to that previously observed to elicit Sz-like alteration in neural circuitry $(16,23)$. Twenty-four hours after the final injection, KA-induced oscillations in layer II/III were characterized from PrL slices collected from either drug treated $(n=9)$ or control animals which received saline injections $(n=7)$. Visual inspection of a grand average of KA-elicited oscillations recorded from animals receiving chronic ketamine $(30 \mathrm{mg} / \mathrm{kg})$ injections revealed a clear reduction in the KA-elicited oscillatory response when compared to saline treated controls (Figure 1).

This data was initially analyzed using the method employed in our earlier acute NMDAR antagonist study (15), which examined the first $5 \mathrm{~s}$ of oscillatory activity immediately following peak frequency (see Figure 2) and in the power in the $(40-50 \mathrm{~Hz})$ band, which is almost absent in slices from drug treated mice $5-10$ s following $\mathrm{KA}$ application. $5 \mathrm{mg} / \mathrm{kg}$ ketamine treatment also appears to show a slight decrease in the higher-frequency elicited response, while the response at lower frequency bands appears elevated (not significant). MK-801 treated mice show a trend toward reduced power but no change in peak frequency (see Figure 2 and text). Insets provide representative examples of GBO signal traces recorded from acute slices from mice in each treatment group (scale bar for insets: $x=200 \mathrm{~ms}, y=50 \mu \mathrm{V}$ ).

the decay of the DC transient caused by KA application (2.5$7.5 \mathrm{~s}$ following KA application). This analysis revealed a significant $\left(t_{13}=3.74, p<0.01\right)$ decrease in the peak frequency (saline: $47.4 \pm 1.2 \mathrm{~Hz}$; ketamine: $40.4 \pm 1.3 \mathrm{~Hz}$ ) of elicited oscillations in slices from chronic ketamine treated mice (Table 1: epoch 1). Both the peak power and total GBO power within the first $5 \mathrm{~s}$ also tended to decrease, but these effects were not statistically significant $\left(t_{13}=1.24, p=0.24\right.$ and $t_{13}=1.18, p=0.26$ respectively).

Visual inspection of the grand averages suggested that oscillatory activity elicited in $30 \mathrm{mg} / \mathrm{kg}$ chronic ketamine treated slices decayed faster than in saline treated animals. Thus, to determine if chronic ketamine treatment impaired the ability of the PrL slice to maintain the KA-elicited GBO, we additionally analyzed the first $30 \mathrm{~s}$ of elicited oscillatory activity subdivided into $5 \mathrm{~s}$ epochs (Figure 2; Table 1). Using this analytical method, a repeated measures ANOVA observed a significant reduction in both the 


\section{A Total Gamma Power}

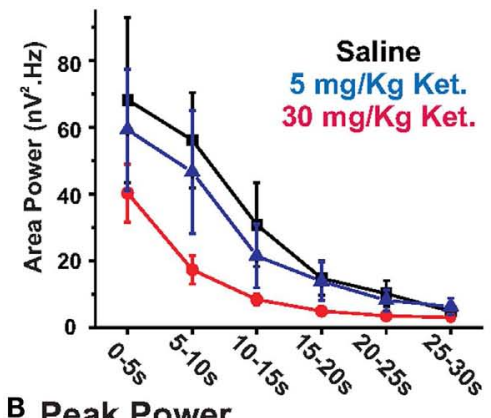

$B$ Peak Power

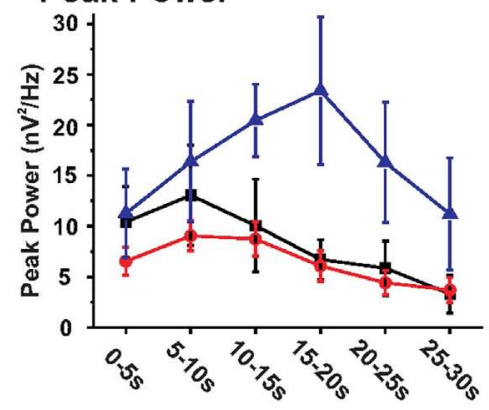

C Peak Frequency

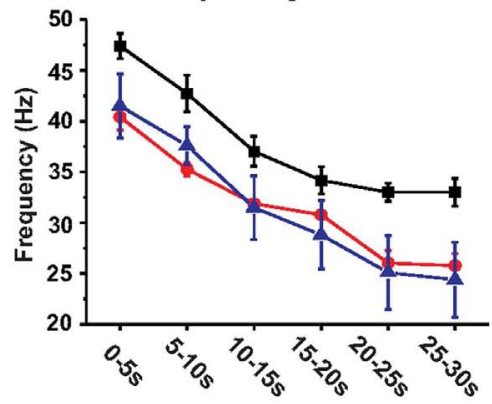

FIGURE 2 | Chronic ketamine treatment leads to decreases in the power and peak frequency of KA-elicited PrL oscillations. Graphs show the effects of chronic ketamine given at daily doses of $5 \mathrm{mg} / \mathrm{kg}$ (blue) or $30 \mathrm{mg} / \mathrm{kg}$ (red) on (A) total GBO power $(40-50 \mathrm{~Hz})$, (B) peak power, and (C) peak frequency across $30 \mathrm{~s}$ of the elicited oscillatory response recorded from acute PrL slices. Compared to saline treated controls (black), mice receiving $30 \mathrm{mg} / \mathrm{kg}$ ketamine showed a significant decrease in both total GBO power (between 5 and 20 s; see Table 1) and the peak frequency of elicited activity. No change was observed in peak power. At $5 \mathrm{mg} / \mathrm{kg}$, chronic ketamine had no significant effect on total GBO power or peak power. While a decrease in peak frequency was still apparent at this concentration, this effect was only significant in the 20-25 and 25-30 s epochs.

peak frequency of elicited oscillations $\left(F_{1,13}=52.77 ; p<0.01\right)$, and total GBO power $\left(F_{1,13}=9.99 ; p<0.01\right)$, across the full $30 \mathrm{~s}$ of KA-elicited activity. No effect was observed on peak power $\left(F_{1,13}=0.46 ; p=0.51\right)$. Further statistical analysis, comparing each epoch individually, showed that the significant decrease in peak frequency observed above was maintained throughout all periods of analyzed activity. While total GBO power was reduced in chronic ketamine treated animals throughout the entire $30 \mathrm{~s}$ of analyzed activity, this reduction was only statistically significant in the second $\left(5-10 \mathrm{~s} ; t_{13}=3.09, p<0.01\right)$, third $\left(10-15 \mathrm{~s} ; t_{13}=2.18\right.$,

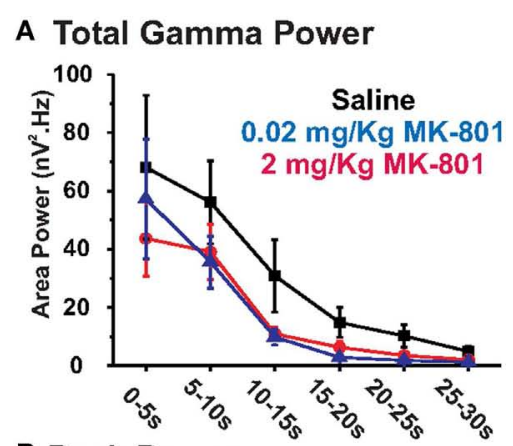

B Peak Power

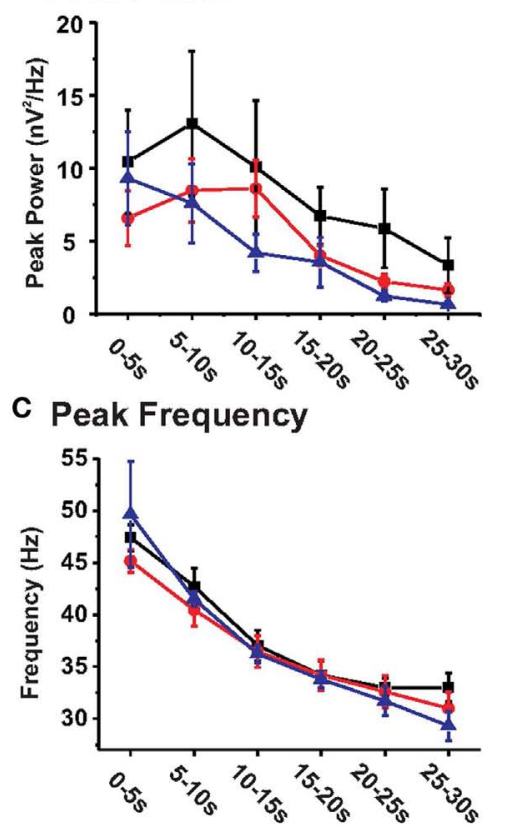

FIGURE 3 | Chronic MK-801 treatment does not significantly alter KA-elicited PrL oscillations. Graphs show the effects of chronic MK-801 given at daily doses of $0.02 \mathrm{mg} / \mathrm{kg}$ (blue) or $2 \mathrm{mg} / \mathrm{kg}$ (red) on (A) total GBO power $(40-50 \mathrm{~Hz}),(\mathbf{B})$ peak power, and (C) peak frequency across $30 \mathrm{~s}$ of the elicited oscillatory response recorded from acute PrL slices, compared to saline treated controls (black). At both concentrations chronic MK-801 treatment resulted in no significant alteration of KA-elicited oscillatory activity.

$p<0.05)$, and fourth $\left(15-20 s ; t_{13}=2.30, p<0.05\right)$ epochs. No significant change in peak power was seen during these periods.

Chronic treatment with a lower concentration of ketamine ( $5 \mathrm{mg} / \mathrm{kg}, n=5$ ), using the same dosing regimen described above conversely appeared to lead to a mild potentiation of the power of the KA-elicited oscillatory response (Figure 1). Nevertheless, analysis of elicited oscillations from these mice revealed that the significant decrease in peak frequency observed with $30 \mathrm{mg} / \mathrm{kg}$ ketamine was also evident at this lower dose (repeated measure ANOVA; $\left.F_{1,9}=6.95 ; p<0.05\right)$. This decrease was of a similar magnitude as observed with the higher ketamine dose when compared across all epochs of analyzed activity at $5 \mathrm{mg} / \mathrm{kg}$, however, it was only significant in epochs 5 and $6\left(t_{9}=2.28, p<0.05 ; t_{9}=2.34\right.$, $p<0.05$, respectively), and reached a trend level of significance 


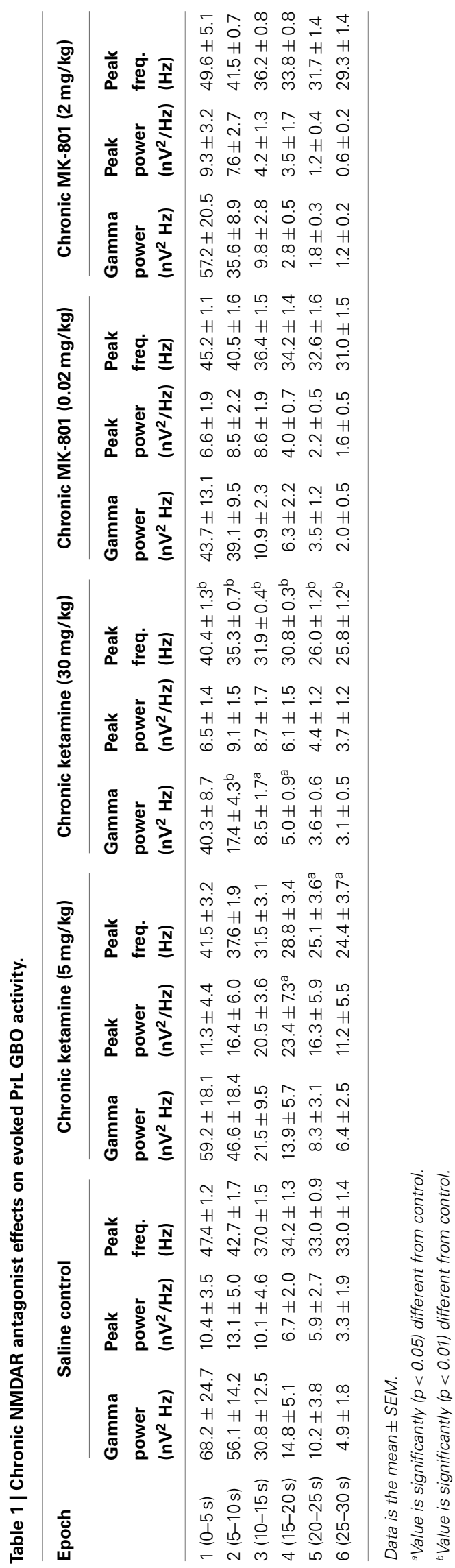

in epochs $1,2,3$, and $4\left(t_{9}=1.87, p=0.10 ; t_{9}=1.98, p=0.08\right.$; $t_{9}=1.70, p=0.13 ; t_{9}=1.75, p=0.12$, respectively). $5 \mathrm{mg} / \mathrm{kg}$ ketamine did not lead to a decrease in the GBO power of KAelicited oscillations (Figure 2). Similarly, no significant changes were found in peak power, compared to saline controls across the entire $30 \mathrm{~s}$ of elicited oscillations analyzed (repeated measures ANOVA). Comparison of individual epochs for total GBO and peak power did reveal a significant increase in peak power in the fourth epoch $\left(15-20 \mathrm{~s} ; t_{9}=-2.54 ; p<0.05\right)$ and a trend level increase in the third $\left(10-15 s ; t_{9}=-1.73 ; p=0.12\right)$ and fifth (20-25 s; $\left.t_{9}=-1.71 ; p=0.12\right)$ epochs, however.

\section{CHRONIC MK-801 REVEALED NO STATISTICALLY SIGNIFICANT EFFECT ON PrL GBO}

While ketamine is commonly used recreationally and clinically to elicit Sz-like effects, several other drugs which inhibit NMDAR activity have also been used to elicit Sz-like behavioral effects in animals $(8,9)$. Thus, we also examined the effect of MK-801, a noncompetitive NMDAR antagonist which is more selective than ketamine, since ketamine has effects on a number of other neurotransmitter receptors $(15,27,28)$. Previous studies have shown that daily injections of $0.02 \mathrm{mg} / \mathrm{kg} \mathrm{MK-801,} \mathrm{were} \mathrm{sufficient} \mathrm{to} \mathrm{induce} \mathrm{Sz-like}$ alterations in neural circuitry, and behavioral effects (24). Thus, we gave mice five daily, i.p. injections of MK-801 $(0.02 \mathrm{mg} / \mathrm{kg})$ or saline, as above. Twenty-four hours after the final injection, KA-induced oscillations were characterized from PrL slices from both drug treated $(n=7)$ and saline control $(n=7)$ animals. As shown in Figure 1, the grand average of KA-elicited oscillations recorded in slices from MK-801 mice also suggested an overall reduction in elicited oscillatory response. Despite this, repeated measure ANOVA analysis of the elicited activity revealed no significant effect on total GBO power $\left(F_{1,11}=3.83 ; p=0.08\right)$, peak frequency $\left(F_{1,11}=1.66 ; p=0.22\right)$, or peak power $\left(F_{1,11}=0.97\right.$; $p=0.35$ ). Comparing across individual epochs (Table 1), while the average GBO power was lower than that observed in saline controls (Figure 3A), these decreases reached only a trend level of significance in epochs $3,4,5$, and $6\left(t_{11}=1.70, p=0.12 ; t_{11}=1.61\right.$, $p=0.14 ; t_{11}=1.79, p=0.10 ; t_{11}=1.63, p=0.13$, respectively). Additionally, no significant $(p>0.05)$ effect was observed on peak power, or peak frequency across the entire range of analyzed KA-elicited activity (Figures 3B,C).

To ensure that the observed lack of effect was not caused by the dose of MK-801 being too low, the above experiments were repeated using first $0.5 \mathrm{mg} / \mathrm{kg}(n=4$; data not shown) and then $2 \mathrm{mg} / \mathrm{kg}$ ( $n=3$; Figure 3). As above, neither higher dose of MK-801 had a significant effect on total GBO power, peak power, or peak oscillatory frequency with either repeated measure ANOVA, or individual epoch analysis. Additionally, increasing the length of chronic drug treatment from 5 to 14 days of daily i.p. injections of $2 \mathrm{mg} / \mathrm{kg}$ MK-801 ( $n=4)$ had no effect on in vitro PrL oscillatory activity compared to saline controls (data not shown).

\section{DISCUSSION}

The results reported in this study represent the first investigation of the effects of chronic ( 5 days) application of NMDAR antagonists, ketamine, and MK-801, on gamma band oscillations (GBO) in the adult mouse neocortex, ex vivo. There were three main 
findings: (1) Administration of chronic subanesthetic ketamine at 30 and $5 \mathrm{mg} / \mathrm{kg}$ reduced the peak frequency of the elicited oscillations; (2) Chronic ketamine at $30 \mathrm{mg} / \mathrm{kg}$ also reduced the power of cortical GBO within the $40-50 \mathrm{~Hz}$ band; (3) Somewhat surprisingly, the effect of ketamine was not mimicked by a more selective NMDAR antagonist, MK-801. In the following sections we discuss these three findings in more detail.

\section{CHRONIC KETAMINE REDUCED THE PEAK OSCILLATORY FREOUENCY OF GBO}

Several studies have suggested that the neocortical circuitry has an intrinsic resonance frequency $(29,30)$. Interestingly, each cortical area appears to have its own dominant frequency with frontal cortices showing a resonance frequency in the beta/gamma bands (30). Although most studies of GBO in Sz focus on changes in the power of oscillations, there is some evidence that $\mathrm{Sz}$ is also associated with a change (decrease) in the peak resonance frequency of cortical circuits. Several studies have reported a reduced $40 \mathrm{~Hz}$ response to auditory steady-state stimulation and a trend toward an increased response at $20 \mathrm{~Hz}(31,32)$. Similarly, visual Gestalt stimuli elicit a lower frequency GBO response in schizophrenics than in healthy individuals (33). More recently, Tononi and colleagues used transcranial magnetic stimulation to probe the natural oscillatory frequency of cortical circuits in Sz (34). Interestingly, Sz subjects showed a significant slowing in the peak frequency of cortical oscillations, with the maximal decrease $(10 \mathrm{~Hz})$ occurring in the prefrontal cortex. Furthermore, the prefrontal natural frequency of individuals with Sz was slower than in any of the healthy control subjects and was correlated with both positive and negative symptoms.

While our previous findings with acute ketamine (15) are not directly comparable to our current chronic findings, due to the different routes of ketamine administration (bath application vs. systemic), it is striking that a similar decrease in the peak oscillatory frequency of KA-elicited oscillations was observed in both experiments. Thus, acute or chronic ketamine application reduced the natural resonance frequency of prefrontal cortical circuits, similar to findings in Sz patients (34). This downward shift in the oscillatory frequency would impair the ability of the circuit to receive and process input in the normal GBO range, as it could no longer reliably follow neuronal input at such high frequencies. This would result in reduced/inappropriate synchronization of neural activity, which would likely contribute to both the psychosis and impaired cognition observed in clinical studies, as well as Sz-like behaviors in animal studies.

\section{CHRONIC KETAMINE REDUCED THE POWER OF NEOCORTICAL GBO}

Many studies of GBO in Sz patients have shown reductions in the power of evoked GBO in a variety of sensory or cognitive paradigms $(35,36)$. Our results here in the mouse prefrontal cortex and those of Ferrarelli et al. (34), in Sz patients suggest that one reason for such decreased GBO power may be a reduction in the peak resonance frequency of cortical circuitry. Another reason may be increased spontaneous, background broadband power due to increased excitability of principal neurons, as observed in genetic models with reduced NMDAR expression in parvalbumin-positive interneurons [see Ref. (37-39)]. In our study, with $30 \mathrm{mg} / \mathrm{kg}$ chronic ketamine we did not observe a broadband increase in power, but rather a decrease in a narrow $40-50 \mathrm{~Hz}$ band around the peak resonance frequency, presumably due to the reduction in this peak frequency (see above). Similarly, in vivo, in adult animals, chronic ketamine reduced GBO activity in the hippocampus (13). In our study, with the lower dose of $5 \mathrm{mg} / \mathrm{kg}$, the data plotted in Figures $\mathbf{1}$ and $\mathbf{2}$ appeared to show increased power compared to saline controls, particularly notable in the 15-20 s epoch. Despite this, statistical analysis (repeated measures ANOVA) indicated that overall this effect was not significant. Thus, we do not believe there is any physiological relevance to the elevated peak power measures observed with $5 \mathrm{mg} / \mathrm{kg}$ ketamine treatment. Together, these results with 30 and $5 \mathrm{mg} / \mathrm{kg}$ ketamine suggest that a higher dose is necessary to observe Sz-like reductions in GBO power.

\section{CHRONIC MK-801 APPLICATION HAD NO STATISTICALLY SIGNIFICANT EFFECT ON PrL GBO}

Surprisingly, we found that chronic treatment with MK-801, a more specific NMDAR antagonist, did not reproduce the Sz-like impairment in elicited PrL GBO caused by chronic ketamine. Increasing the concentration of MK-801 or the duration of application did not change the response. Disparity in the efficacy of different NMDAR antagonists in mimicking Sz-like effects have also been observed in other studies. For instance, a recent study compared the behavioral effects of chronic PCP, a similarly promiscuous pharmacological agent to ketamine, and MK801 in rodents (40). This study found that MK-801 treatment did not replicate the full spectrum of behavioral impairments induced by PCP. What accounts for these differences between Ketamine/PCP and MK-801? One possibility is that chronic suppression of NMDAR function by itself may not be enough to elicit the behavioral/electrophysiological effect. Ketamine, in particular, has actions on several other neurotransmitter receptors such as $\mathrm{D}_{2}$ receptors, 5- $\mathrm{HT}_{2}$ receptors, and $\mathrm{GABA}_{\mathrm{A}}$ receptors $(15,27,28,41)$. Another possibility is that differences in the pharmacokinetics of these drugs affect the results. Thus, differences in the peak concentration, tissue penetration, and duration of action may affect the resultant changes in neocortical circuitry. While the precise mechanism has yet to be defined, our results, and those of others, suggest that chronic ketamine better models Sz-like changes in cortical function than chronic MK-801.

\section{CONCLUSION}

Here we show, ex vivo, that chronic ketamine at $30 \mathrm{mg} / \mathrm{kg}$ results in Sz-like impairment of both the frequency and power of KA-elicited GBO in the PrL. This combined reduction in power and frequency is reminiscent of earlier clinical findings associated with cognitive deficits in Sz patients (31, 33-35). Our observation of these findings in an acute slice preparation provide strong evidence that the chronic ketamine mediated effects are mediated by local circuit alterations in the PrL. While important in establishing the locus of changes in oscillatory activity, one important limitation when comparing our ex vivo approach with clinical studies is that our slice preparation lacks input from other brain regions important in generating GBO activity in vivo. Thus, future studies testing the effect of chronic ketamine in vivo, utilizing transcranial magnetic 
stimulation, or other means, to generate GBO will be important for corroborating our results.

Acutely, NMDAR blockade leads to increased excitability of pyramidal neurons (42), altering the balance of excitation and inhibition in the cortical circuitry. Thus, we speculate that in our system chronic ketamine treatment leads to changes in the cortical circuitry in the PrL resulting over time in circuit dysfunction, perhaps through excitotoxicity (43) and/or upregulation of oxidative pathways (25). While we did not directly examine the cellular mechanisms behind this effect in this study, computational modeling suggests that either reductions in the number of PV interneurons or a reduction in GAD67 could account for our findings of reduced GBO power and peak frequency $(44,45)$.

\section{REFERENCES}

1. Gogolla N, Leblanc JJ, Quast KB, Sudhof TC, Fagiolini M, Hensch TK. Common circuit defect of excitatory-inhibitory balance in mouse models of autism. J Neurodev Disord (2009) 1: 172-81. doi:10.1007/s11689-0099023-x

2. Woo TU, Spencer K, McCarley RW. Gamma oscillation deficits and the onset and early progression of schizophrenia. Harv Rev Psychiatry (2010) 18:173-89. doi:10.3109/ 10673221003747609

3. McNally JM, McCarley RW, Brown RE. Impaired GABAergic neurotransmission in schizophrenia underlies impairments in cortical gamma band oscillations. Curr Psychiatry Rep (2013) 15:346. doi:10. 1007/s11920-012-0346-z

4. Buzsaki G, Draguhn A. Neuronal oscillations in cortical networks. Science (2004) 304:1926-9. doi:10. 1126/science.1099745

5. Uhlhaas PJ, Haenschel C, Nikolic D, Singer W. The role of oscillations and synchrony in cortical networks and their putative relevance for the pathophysiology of schizophrenia. Schizophr Bull (2008) 34:927-43. doi:10.1093/schbul/sbn062

6. Buzsaki G. Rhythms of the Brain. New York: Oxford University Press (2006).

7. Lewis DA, Gonzalez-Burgos G. Neuroplasticity of neocortical circuits in schizophrenia. Neuropsychopharmacology (2008) 33:141-65. doi:10.1038/sj.npp.1301563

8. Bubenikova-Valesova V, Horacek J, Vrajova M, Hoschl C. Models of schizophrenia in humans and animals based on inhibition of NMDA receptors. Neurosci Biobehav Rev (2008) 32:1014-23. doi:10.1016/j. neubiorev.2008.03.012

9. Corlett PR, Honey GD, Krystal JH, Fletcher PC. Glutamatergic model psychoses: prediction error, learning, and inference. Neuropsychopharmacology (2011)
36:294-315. doi:10.1038/npp.2010. 163

10. Gilmour G, Dix S, Fellini L, Gastambide F, Plath N, Steckler T, et al. NMDA receptors, cognition and schizophrenia - testing the validity of the NMDA receptor hypofunction hypothesis. Neuropharmacology (2012) 62:1401-12. doi:10.1016/j.neuropharm.2011.03. 015

11. Pinault D. N-methyl D-aspartate receptor antagonists ketamine and MK-801 induce wakerelated aberrant gamma oscillations in the rat neocortex. Biol Psychiatry (2008) 63: 730-5. doi:10.1016/j.biopsych. 2007.10.006

12. Hakami T, Jones NC, Tolmacheva EA, Gaudias J, Chaumont J, Salzberg $\mathrm{M}$, et al. NMDA receptor hypofunction leads to generalized and persistent aberrant gamma oscillations independent of hyperlocomotion and the state of consciousness. PLoS One (2009) 4:e6755. doi:10. 1371/journal.pone.0006755

13. Kittelberger K, Hur EE, Sazegar S, Keshavan V, Kocsis B. Comparison of the effects of acute and chronic administration of ketamine on hippocampal oscillations: relevance for the NMDA receptor hypofunction model of schizophrenia. Brain Struct Funct (2012) 217:395-409. doi:10.1007/s00429011-0351-8

14. Anver H, Ward PD, Magony A, Vreugdenhil M. NMDA receptor hypofunction phase couples independent gamma-oscillations in the rat visual cortex. Neuropsychopharmacology (2010) 36:519-28. doi:10. 1038/npp.2010.183

15. McNally JM, McCarley RW, McKenna JT, Yanagawa Y, Brown RE. Complex receptor mediation of acute ketamine application on in vitro gamma oscillations in mouse prefrontal cortex: modeling gamma band oscillation abnormalities in schizophrenia. Neuroscience

Our findings support the idea that deficits in executive function observed with chronic administration of ketamine in humans and animals $(8,9,46-48)$ are due to an impaired ability of neocortical circuitry to generate and/or maintain the proper frequency oscillations and synchronicity necessary to bind together relevant information.

\section{ACKNOWLEDGMENTS}

This study was supported by both the VA and the National Institute of Mental Health (NIMH) RO1 grant MH040799 "Neurophysiological studies of Schizophrenia" (Robert W. McCarley) and R21 grant MH094803 "Modeling schizophrenia gamma deficits using cell-specific RNAi knockdown of GAD67" (Ritchie E. Brown).

(2011) 199:51-63. doi:10.1016/j. neuroscience.2011.10.015

16. Zhang Y, Behrens MM, Lisman JE. Prolonged exposure to NMDAR antagonist suppresses inhibitory synaptic transmission in prefrontal cortex. $\mathrm{J} \mathrm{Neu}$ rophysiol (2008) 100:959-65. doi:10.1152/jn.00079.2008

17. Xi D, Zhang W, Wang HX, Stradtman GG, Gao WJ. Dizocilpine (MK-801) induces distinct changes of N-methyl-D-aspartic acid receptor subunits in parvalbumincontaining interneurons in young adult rat prefrontal cortex. Int $J$ Neuropsychopharmacol (2009) 12:1395-408 doi:10.1017/S146114570900042X

18. Vertes RP. Differential projections of the infralimbic and prelimbic cortex in the rat. Synapse (2004) 51:32-58. doi:10.1002/syn.10279

19. Berman KF, Zec RF, Weinberger DR. Physiologic dysfunction of dorsolateral prefrontal cortex in schizophrenia. II. Role of neuroleptic treatment, attention, and mental effort. Arch Gen Psychiatry (1986) 43:126-35. doi:10.1001/ archpsyc.1986.01800020032005

20. Weinberger DR, Berman KF, Zec RF. Physiologic dysfunction of dorsolateral prefrontal cortex in schizophrenia. I. Regional cerebral blood flow evidence. Arch Gen Psychiatry (1986) 43:114-24. doi:10.1001/archpsyc. 1986.01800020020004

21. Tamamaki N, Yanagawa Y, Tomioka R, Miyazaki J, Obata K, Kaneko T. Green fluorescent protein expression and colocalization with calretinin, parvalbumin, and somatostatin in the GAD67-GFP knockin mouse. J Comp Neurol (2003) 467:60-79. doi:10.1002/cne.10905

22. Behrens MM, Ali SS, Dugan LL. Interleukin-6 mediates the increase in NADPH-oxidase in the ketamine model of schizophrenia. J Neurosci (2008) 28:13957-66. doi:10.1523/ JNEUROSCI.4457-08.2008
23. Keilhoff G, Becker A, Grecksch G Wolf G, Bernstein HG. Repeated application of ketamine to rats induces changes in the hippocampal expression of parvalbumin, neuronal nitric oxide synthase and cFOS similar to those found in human schizophrenia. Neuroscience (2004) 126:591-8. doi:10.1016/j. neuroscience.2004.03.039

24. Rujescu D, Bender A, Keck M, Hartmann AM, Ohl F, Raeder $\mathrm{H}$, et al. A pharmacological model for psychosis based on $\mathrm{N}$-methyl-D-aspartate receptor hypofunction: molecular, cellular, functional and behavioral abnormalities. Biol Psychiatry (2006) 59: 721-9. doi:10.1016/j.biopsych. 2005.08.029

25. Behrens MM, Ali SS, Dao DN, Lucero J, Shekhtman G, Quick KL, et al. Ketamine-induced loss of phenotype of fast-spiking interneurons is mediated by NADPH-oxidase. Science (2007) 318:1645-7. doi:10. 1126/science.1148045

26. Franklin K, Paxinos G. The Mouse Brain in Stereotaxic Coordinates. New York: Elsevier Press (2008).

27. Irifune $M$, Sato $T$, Kamata $Y$, Nishikawa T, Dohi T, Kawahara M. Evidence for GABA(A) receptor agonistic properties of ketamine: convulsive and anesthetic behavioral models in mice. Anesth Analg (2000) 91:230-6. doi:10. 1213/00000539-200007000-00043

28. Kapur S, Seeman P. NMDA receptor antagonists ketamine and PCP have direct effects on the dopamine $\mathrm{D}(2)$ and serotonin 5-HT(2)receptors-implications for models of schizophrenia. Mol Psychiatry (2002) 7:837-44. doi:10.1038/sj.mp.4001093

29. Gray CM, Konig P, Engel AK, Singer W. Oscillatory responses in cat visual cortex exhibit intercolumnar synchronization which reflects global stimulus properties. Nature (1989) 338:334-7. doi:10. $1038 / 338334 \mathrm{a} 0$ 
30. Rosanova M, Casali A, Bellina V, Resta F, Mariotti M, Massimini M. Natural frequencies of human corticothalamic circuits. J Neurosci (2009) 29:7679-85. doi:10.1523/JNEUROSCI.0445-09. 2009

31. Kwon JS, O’Donnell BF, Wallenstein GV, Greene RW, Hirayasu Y, Nestor $\mathrm{PG}$, et al. Gamma frequency-range abnormalities to auditory stimulation in schizophrenia. Arch Gen Psychiatry (1999) 56:1001-5. doi:10. 1001/archpsyc.56.11.1001

32. Vierling-Claassen D, Siekmeier P, Stufflebeam S, Kopell N. Modeling GABA alterations in schizophrenia: a link between impaired inhibition and altered gamma and beta range auditory entrainment. J Neurophysiol (2008) 99:2656-71. doi:10.1152/ jn.00870.2007

33. Spencer KM, Nestor PG, Perlmutter R, Niznikiewicz MA, Klump MC, Frumin M, et al. Neural synchrony indexes disordered perception and cognition in schizophrenia. Proc Natl Acad Sci U S A (2004) 101:17288-93. doi:10.1073/ pnas.0406074101

34. Ferrarelli F, Sarasso S, Guller Y, Riedner BA, Peterson MJ, Bellesi M, et al. Reduced natural oscillatory frequency of frontal thalamocortical circuits in schizophrenia. Arch Gen Psychiatry (2012) 69:766-74. doi:10.1001/archgenpsychiatry. 2012.147

35. Spencer KM, Nestor PG, Niznikiewicz MA, Salisbury DF, Shenton ME, McCarley RW. Abnormal neural synchrony in schizophrenia. J Neurosci (2003) 23:7407-11.
36. Uhlhaas PJ, Singer W. Abnormal neural oscillations and synchrony in schizophrenia. Nat Rev Neurosci (2010) 11:100-13. doi:10. 1038/nrn2774

37. Korotkova T, Fuchs EC, Ponomarenko A, Von Engelhardt J, Monyer H. NMDA receptor ablation on parvalbuminpositive interneurons impairs hippocampal synchrony, spatial representations, and working memory. Neuron (2010) 68:557-69. doi:10.1016/j.neuron.2010.09.017

38. Carlen M, Meletis K, Siegle JH, Cardin JA, Futai K, VierlingClaassen D, et al. A critical role for NMDA receptors in parvalbumin interneurons for gamma rhythm induction and behavior. Mol Psychiatry (2012) 17:537-48. doi:10.1038/ mp.2011.31

39. Gandal MJ, Sisti J, Klook K, Ortinski PI, Leitman V, Liang Y, et al. GABAB-mediated rescue of altered excitatory-inhibitory balance, gamma synchrony and behavioral deficits following constitutive NMDAR-hypofunction. Transl Psychiatry (2012) 2:e142. doi:10. 1038/tp.2012.69

40. Seillier A, Giuffrida A. Evaluation of NMDA receptor models of schizophrenia: divergences in the behavioral effects of sub-chronic PCP and MK-801. Behav Brain Res (2009) 204:410-5. doi:10.1016/j.bbr.2009. 02.007

41. Flood P, Krasowski MD. Intravenous anesthetics differentially modulate ligand-gated ion channels. Anesthesiology (2000) 92:1418-25. doi:10.1097/ 00000542-200005000-00033
42. Homayoun H, Moghaddam B. NMDA receptor hypofunction produces opposite effects on prefrontal cortex interneurons and pyramidal neurons. J Neurosci (2007) 27:11496-500. doi:10.1523/ JNEUROSCI.2213-07.2007

43. Olney JW, Labruyere J, Wang G, Wozniak DF, Price MT, Sesma MA. NMDA antagonist neurotoxicity: mechanism and prevention. Science (1991) 254:1515-8. doi:10. 1126/science.1835799

44. Spencer KM. The functional consequences of cortical circuit abnormalities on gamma oscillations in schizophrenia: insights from computational modeling. Front Hum Neurosci (2009) 3:33. doi:10.3389/ neuro.09.033.2009

45. Volman V, Behrens MM, Sejnowski TJ. Downregulation of parvalbumin at cortical GABA synapses reduces network gamma oscillatory activity. J Neurosci (2011) 31:18137-48 doi:10.1523/JNEUROSCI.3041-11. 2011

46. Krystal JH, Karper LP, Seibyl JP, Freeman GK, Delaney R, Bremner JD, et al. Subanesthetic effects of the noncompetitive NMDA antagonist, ketamine, in humans. Psychotomimetic, perceptual, cognitive, and neuroendocrine responses. Arch Gen Psychiatry (1994) 51:199-214. doi:10.1001/ archpsyc.1994.03950030035004

47. Jentsch JD, Roth RH. The neuropsychopharmacology of phencyclidine: from NMDA receptor hypofunction to the dopamine hypothesis of schizophrenia. Neuropsychopharmacology (1999) 20:201-25. doi:10. 1016/S0893-133X(98)00060-8
48. Pomarol-Clotet E, Honey GD, Murray GK, Corlett PR, Absalom AR, Lee $\mathrm{M}$, et al. Psychological effects of ketamine in healthy volunteers. Phenomenological study. Br J Psychiatry (2006) 189:173-9. doi:10.1192/ bjp.bp. 105.015263

Conflict of Interest Statement: The editor, Bernat Kocsis, and several authors of this manuscript (Ritchie Brown and Robert McCarley) recently coauthored a review article and have collaborated on funded and unfunded NIH research grants. However, Dr Kocsis was not involved in the design, execution, analysis or writing of the work presented in this manuscript.

Received: 14 June 2013; accepted: 31 August 2013; published online: 17 September 2013.

Citation: McNally JM, McCarley RW and Brown RE (2013) Chronic ketamine reduces the peak frequency of gamma oscillations in mouse prefrontal cortex ex vivo. Front. Psychiatry 4:106. doi: 10.3389/fpsyt.2013.00106

This article was submitted to Schizophrenia, a section of the journal Frontiers in Psychiatry.

Copyright (c) 2013 McNally, McCarley and Brown. This is an open-access article distributed under the terms of the Creative Commons Attribution License (CC $B Y)$. The use, distribution or reproduction in other forums is permitted, provided the original author(s) or licensor are credited and that the original publication in this journal is cited, in accordance with accepted academic practice. No use, distribution or reproduction is permitted which does not comply with these terms. 